\title{
Prevalence of prediabetes according to hemoglobin A1c versus fasting plasma glucose criteria in healthy adults
}

\author{
Jonas Blum • Stefanie Aeschbacher - Tobias Schoen • \\ Matthias Bossard · Katrin Pumpol • Noé Brasier • \\ Martin Risch • Lorenz Risch • David Conen
}

Received: 10 September 2014/ Accepted: 22 September 2014/Published online: 25 October 2014

(C) Springer-Verlag Italia 2014

Keywords Prediabetes · Diagnosis - Hemoglobin A1c · Fasting plasma glucose $\cdot$ Gender

Current American Diabetes Association Guidelines recommend either glycated hemoglobin $\left(\mathrm{HbA}_{1 \mathrm{c}}\right)$ or fasting plasma glucose (FPG) as screening tools for diagnosing diabetes mellitus [1]. However, there is conflicting evidence regarding the correlation between these two measures $[2,3]$. This issue is particularly important in a

Managed by Massimo Federici.

J. Blum - S. Aeschbacher - T. Schoen - M. Bossard .

K. Pumpol · N. Brasier · D. Conen $(\varangle)$

Department of Medicine, University Hospital Basel,

Petersgraben 4, 4031 Basel, Switzerland

e-mail: David.Conen@usb.ch

J. Blum $\cdot$ S. Aeschbacher $\cdot$ T. Schoen $\cdot$ M. Bossard .

K. Pumpol · N. Brasier · D. Conen

Cardiovascular Research Institute Basel, University Hospital

Basel, Spitalstrasse 2, 4031 Basel, Switzerland

\section{Bossard}

Cardiology Division, University Hospital Basel, Petersgraben 4, 4031 Basel, Switzerland

\section{Risch · L. Risch}

Labormedizinisches Zentrum Dr Risch, Schaan, Liechtenstein

\section{Risch}

Division of Laboratory Medicine, Kantonsspital Graubünden,

Chur, Switzerland

L. Risch

Division of Clinical Biochemistry, Medical University,

Innsbruck, Austria

L. Risch

Private University, Triesen, Liechtenstein population of young and healthy adults who will undergo repetitive screening examinations. We therefore aimed to evaluate the performance of both $\mathrm{HbA}_{1 \mathrm{c}}$ and FPG as tools to diagnose prediabetes in a large sample of young and healthy adults.

We conducted a cross-sectional analysis of healthy adults aged 25-41 years participating in a prospective cohort study [4]. Individuals with known diabetes, body mass index $(\mathrm{BMI})>35 \mathrm{~kg} / \mathrm{m} 2$, and prevalent cardiovascular disease were excluded such that a total of 1,542 participants remained in this analysis. Detailed information about the study methodology has been published previously [4]. Prediabetes was defined as an $\mathrm{HbA}_{1 \mathrm{c}}$ of 5.7-6.4 \% and/or an FPG of 5.6-6.9 mmol/1 [1]. Prediabetic individuals were classified as being diagnosed either by $\mathrm{HbA}_{1 \mathrm{c}}$, FPG, or by both criteria. Multivariable logistic regression models among individuals with prediabetes were used to evaluate independent risk factors predisposing to a diagnosis of prediabetes with $\mathrm{HbA}_{1 \mathrm{c}}$ only.

Prediabetes was diagnosed in 477 (30.9\%) individuals (36.8\% among men, $25.8 \%$ among women, $p<0.0001$ ). The diagnosis was obtained by $\mathrm{HbA}_{1 \mathrm{c}}$ only in 381 (79.9\%), by FPG only in 47 (9.9\%) individuals, and by both tests in $49(10.3 \%)$ individuals. The Pearson's correlation coefficient between $\mathrm{HbA}_{1 \mathrm{c}}$ and FPG was 0.26. Individuals diagnosed by elevated $\mathrm{HbA}_{1 \mathrm{c}}$ only were more likely to be female (91.0 vs. $71.1 \%$ among men, $p<0.0001)$, less likely to be obese (61.6 vs. $83.2 \%$ among non-obese, $p<0.0001$ ), and less likely to be hypertensive (65.8 vs. $82.8 \%$ among non-hypertensives). Insulin and Homeostatic model assessment of insulin resistance (HOMA-IR) [5] levels significantly differed across the four groups (Fig. 1).

In multivariable logistic regression analyses, sex (OR $4.14,95 \%$ CI $1.81-9.45, p=0.0008$ ), past smoking (OR 
Fig. 1 Insulin levels and HOMA insulin resistance among prediabetic groups

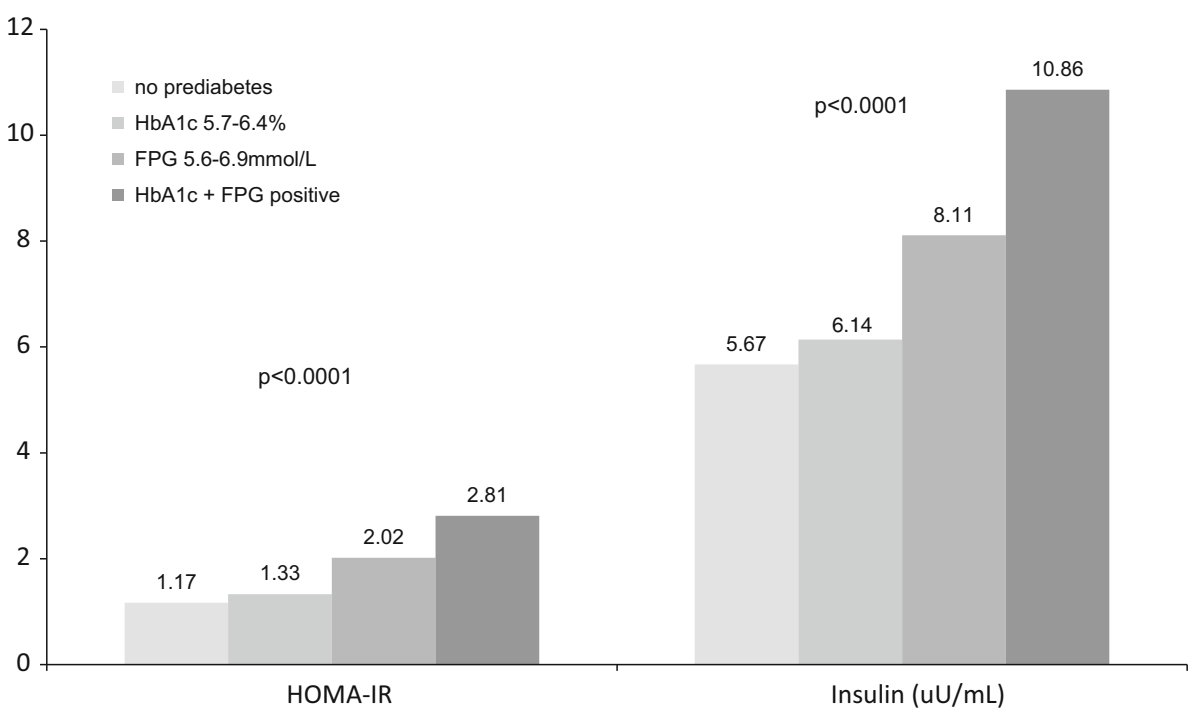

0.47, $95 \%$ CI 0.24-0.92, $p=0.03$ ), alcohol consumption (OR 0.93, $95 \%$ CI 0.87-0.99, $p=0.03$ ), and HOMA-IR (OR 0.40, $95 \%$ CI 0.29-0.56, $p<0.0001$ ) were independent predictors for a diagnosis of prediabetes by $\mathrm{HbA}_{1 \mathrm{c}}$ criteria only.

In conclusion, the prevalence of prediabetes among young and healthy adults was highly dependent on the test used and was much higher using $\mathrm{HbA}_{1 \mathrm{c}}$ criteria, especially among women. The correlation between $\mathrm{HbA}_{1 \mathrm{c}}$ and FPG was modest. If confirmed, our findings may have important implications for screening recommendations in the population, and may lead to an increase in the prevalence of prediabetes in healthy adults. From a mechanistic perspective, our results suggest that those diagnosed by $\mathrm{HbA}_{1 \mathrm{c}}$ only have a lower insulin resistance than those diagnosed by an elevated FPG.

Acknowledgments The Liechtenstein Government, the Swiss Heart Foundation, the Swiss Society of Hypertension, the University of Basel, the University Hospital Basel, the Hanela Foundation, Schiller AG and Novartis supported the GAPP study. David Conen was supported by a grant of the Swiss National Science Foundation (PP00P3_133681). Insulin was measured free of charge by Singulex, Alameda, CA 94502, USA.

Conflict of interest Jonas Blum, Stefanie Aeschbacher, Tobias Schoen, Matthias Bossard, Katrin Pumpol, Noé Brasier, Martin Risch, Lorenz Risch, and David Conen declare that they have no conflict of interest.
Human and Animal Rights disclosure All procedures followed were in accordance with the ethical standards of the responsible committee on human experimentation (institutional and national) and with the Declaration of Helsinki 1975, as revised in 2008.

Informed consent disclosure Informed consent was obtained from all patients for being included in the study.

\section{References}

1. American Diabetes A (2013) Diagnosis and classification of diabetes mellitus. Diabetes Care 36(Suppl 1):S67-S74. doi:10. 2337/dc13-S067

2. Saukkonen T, Cederberg H, Jokelainen J, Laakso M, Harkonen P, Keinanen-Kiukaanniemi S, Rajala U (2011) Limited overlap between intermediate hyperglycemia as defined by A1C 5.7-6.4\%, impaired fasting glucose, and impaired glucose tolerance. Diabetes Care 34(10):2314-2316. doi:10.2337/dc11-0183

3. James C, Bullard KM, Rolka DB, Geiss LS, Williams DE, Cowie CC, Albright A, Gregg EW (2011) Implications of alternative definitions of prediabetes for prevalence in U.S. adults. Diabetes Care 34(2):387-391. doi:10.2337/dc10-1314

4. Conen D, Schon T, Aeschbacher S, Pare G, Frehner W, Risch M, Risch L (2013) Genetic and phenotypic determinants of blood pressure and other cardiovascular risk factors (GAPP). Swiss Med Wkly 143:w13728. doi:10.4414/smw.2013.13728

5. Matthews DR, Hosker JP, Rudenski AS, Naylor BA, Treacher DF, Turner RC (1985) Homeostasis model assessment: insulin resistance and beta-cell function from fasting plasma glucose and insulin concentrations in man. Diabetologia 28(7):412-419 